\title{
REPORT ON LEPROSY IN JAMAICA
}

\author{
E. MUIR
}

At the request of the Director of Medical Services and on behalf of the British Empire I.eprosy Relief Association, I visited Jamaica from the 5th to the 26th of August, 1942. The visit was also made at the request of the Medical Adviser to the Comptroller for Development and Welfare in the West Indies.

\section{OBJECTS OF VISIT.}

The objects of the visit were to study leprosy as it is found in the island, and to make any recommendations thought necessary towards the control and relief of the disease.

Six days were spent at the Leper Asylum at Spanish Town, during which each case was inspected and classified an attempt being made as far as possible to trace the source of infection. The visiting Medical Attendant and the Sisters were advised regarding methods of treatment, special cases being prescribed for.

I was present at a meeting of the Official Visiting Board and discussed with the members the proposals for improving the I.eper Asylum. I also gave a talk to the patients on the nature of leprosy and the ways in which they themselves may facilitate their recovery.

Visits were made to the parishes of Clarendon, Trelawny and St. Ann and most of the cases living at home in the latter two parishes were seen and discussed with the Medical Officers of Health.

A lecture-demonstration was arranged by the Jamaica Branch of the British Medical Association, at which about 45 Doctors, Health Nurses and Sanitary Inspectors were present, and a further demonstration was given at the Leper Asylum to the Medical Officers of Health and other doctors, which was also attended hy the Sisters. A public meeting was to be held in Kingston, but had to be cancelled because of the weather.

\section{I.EPER ASYI.UM.}

Site, StafF, Diet.

The I.eper Asylum is situated on the outskirts of Spanish Town, the old capital of Jamaica, about 13 miles from Kingston. It is surrounded by a concrete wall and sheet-iron 
fence, and the male and female quarters are separated by a sheet-iron fence. The patients are housed in dormitories which are considerably congested, and no arrangement has been made to separate the different types (neural and lepromatous) of cases. The staft consists of a part-time visiting medical attendant and six Sisters, who are responsible for administration and treatment. Recently several acres of adjoining land have been acquired for new buildings and for patients' gardens. I understand that it is proposed to relinquish the present male dormitories for the additional use of female patients. I understand that money has been voted by Government for this purpose, but that delay is caused by the difficulty of obtaining materials at the present time.

The Sisters belong to a Catholic Order. They were installed about two years ago, and it is obvious that considerable improvements have taken place during that time.

The patients are supplied, except for one or two paying patients, with free diet, which, as far as I could gather, appears to be adequate both in quality and quantity.

\section{Classification of Patients.}

One hundred and seventy-five of the patients were examined and classified as in Table I. Two male patients had been sent away for punishment.

Table 1.

\begin{tabular}{|c|c|c|c|c|c|c|}
\hline \multirow{3}{*}{ Lepromatous } & & & & Male & Female & Total \\
\hline & $(\mathrm{L}-3)$ & Open & Cases & 48 & 38 & 86 \\
\hline & $(L-2)$ & ," & ," & 5 & 6 & II \\
\hline \multirow{4}{*}{ Neural } & $(\mathrm{L}-\mathrm{I})$ & ," & ," & 7 & I & 8 \\
\hline & $(\mathrm{N}-3)$ & ," & , & 5 & 19 & 24 \\
\hline & $(\mathrm{N}-2)$ & ," & ," & 5 & 7 & 12 \\
\hline & $(\mathrm{N}-\mathrm{I})$ & ," & ," & - & 2 & 2 \\
\hline \multicolumn{4}{|c|}{ Disease Arrested } & 16 & 13 & 29 \\
\hline \multirow{2}{*}{\multicolumn{4}{|c|}{ Not suffering from Leprosy }} & - & 3 & 3 \\
\hline & & & & 86 & 89 & 175 \\
\hline
\end{tabular}

To simplify the classification, mixed cases have been counted as lepromatous. It will be noticed that though the sexes are equal in number there were 60 lepromatous males to 45 females, and 10 neural males to 28 females, indicating that, as is generally the case, leprosy is less serious among women.

In three female patients I could find no indication that there had ever been leprosy. These three and many of the 
29 arrested cases might, with advantage, be discharged so as to make room for admission of other open cases outside who are at present a danger to the community.

Several of the neural cases would probably become arrested in a few months' time if they were treated with intradermal injections, and their subsequent discharge would atford further room.

Provision would have to be made for many of the discharged patients, especially. those who are crippled and disfigured as the result of the disease. I suggest that as far as possible they be quartered near their relatives. A small grant might be made for the erection of a. hut and five shillings a week provided for food, an occasional sum being given for clothes. I understand that relatives often refuse to provide for ex-lepers; but probably most of their objections would disappear if the above provisions were made. Also much of the unpopularity of the Leper Home would vanish if people realised that admission to the home does not necessarily mean exile for life. Such a scheme would not only be more popular but considerably cheaper than one based upon a separate institution for lodging discharged lepers in one place. More work might be thrown upon the Medical Officer of Health, in supervision of discharged patients, but the supervision of ex-neural cases would only involve very occasional visits, and the number of ex-lepromatous cases requiring more frequent visits would be small.

Besides the need for more and better accommodation there are many other things urgently required which I have found supplied in all but smallest and most primitive leprosy institutions. A few of the necessities are enumerated below.

(I) An operation room and surgical instruments and appliances. Many of the cases are badly in need of surgical attention and much suffering and maiming might be prevented if proper provision were made for surgical care.

(2) A laboratory with microscope, stains and other appliances. It is important that frequent bacteriological examinations be made, and laboratory and clinical findings be co-ordinated, if individual study of cases and suitable treatment are to be attempted. Laboratory work could be undertaken by one of the Sisters under the supervision of the doctor.

(3) Dental Clinic. One of the most serious complicating conditions in leprosy is septic teeth and gums. As 
in the Trinidad leprosarium this work could be undertaken by one of the Sisters after she had undergone trainming in dental work.

(4) A Motor Van. 'I his could be used as an ambulance tor bringing in patients trom outlying districts. It could also be used for taking patients out into the country and especially to the seaside. Anyone visiting the Leper Asylun, and particularly the women's quarters, cannot lielp realising the cramped conditions in which the patients are confmed. Visits to the seaside would to a certan extent alleviate this defect and improve the patients' health.

(5) Provision for employment, such as a suitable workshop, etc. As in other leprosy institutions, the patients should be encouraged to employ themselves in useful activities. Uccupation therapy is the most important factor 11 the treatment of leprosy. The Sisters have already made a beginning 11 this direction, but their efforts are handicapped by want of appliances.

1 have read the recommendations recently made by the Board of Visitors, and 1 should like to endorse and emphasise the need for increased accommodation. There should be as far as possible separate cubicles, or at least small cottages for not more than 4 or 0 patients. It is small wonder that better class patrents object to herding together for years on end in large dormitories.

I consider it important that "closed" cases should be housed in separate quarters and not be allowed to mix, at least at nights, with "open"' cases. This would be particularly important if, as is suggested below, early neural cases, especi. ally those found among schoolchildren, are admitted for shor periods of treatment.

Formerly children born in the Leper Asylum were not removed and some of them became infected with the disease. The present arrangement is an excellent one, by which children are removed at birth and sent to the Salvation Army Home. Since 1928 no fewer than 25 children have been sent there; of these 6 have died. I examined the remaining 19 children at the Home and found them all in good health and showing no signs of leprosy.

I consider that the patients should be given the full wholesale value for their garden produce, but that production should be limited to and in accordance with, the vegetables required for the institution. 
I consider that every open case of leprosy should be compulsornly isolated in the institution, with only a few exceptions in cases approved by the Director of Medical Services and under very careful supervision. Suitable accommodation would, however, have to be arranged for better-class patients.

I agree with the Board's recommendations regarding an incinerator, nightsoil and sewage disposal, erecting of more suitable fences, and draining of the surrounding land.

I consider that it should be possible, as in other similar institutions, for the Medical Officer (subject to the approval of the Director of Medical Services) to enforce discipline for small offences by immediate punishment, using either fines or cell detention. The knowledge by the patients that he had such powers would tend to lessen the need for their exercise.

The site of the Leper As;lum is undoubtedly a most unsuitable one. There are five requirements for a suitable site:

(I) It must be healthy or capable of being mad. healthy. I understand that malaria is common in the present site, and malaria is one of the most serious intpediments in the effective treatment of leprosy. The humidity and high temperature of Spanish Town also render it unsuitable.

(2) A leprosy institution should be far enough away from surrounding dwellings to render mixing with healthy people difficult or impossible. The present site is far too near to Spanish Town.

(3) Plenty of agricultural land.

(4) Easy communication for bringing in supplies, and for the relief of the staff.

(5) Abundant water supply for domestic and agricultural purposes.

I understand that in these last three respects the present site is not unsuitable. Doubtless, removal of the instituution to a more healthy and better isolated place is impracticable at the present time, and everything possible should be done to improve the present site and buildings on a temporary basis. I have studied the plans for the improvement of the Asylum and consider that many of the present deficiencies will be relieved when the new buildings are erected and the old ones repaired. 


\section{SPREAD OI' INFECTION.}

Questioning of the 172 leprous patients examined in the Leper Asylum elicited a definite history of what might be considered effective contact in 74 cases and of the probable source of infection in 21 others. In 77 cases no history of contact with open cases could be discovered in the short time available for the examination of each patient, though further investigations would probably have considerably lowered this number.

Patients were divided into three categories: (a) those who had spent some years in Cuba or Panama, (b) those who had spent some years in Kingston but had never been abroad, (c) those who had lived only in rural areas and never been in Kingston or abroad. Table II shows the proportion of definite, probable and negative histories in each of these groups.

Table II.

Cubaetc. Kingston Rural Areas Totals

\begin{tabular}{|c|c|c|c|}
\hline Definite History & $3(17 \%)$ & IO $(42 \%)$ & 6I $(47 \%)$ \\
\hline Probable History & $2(\mathrm{II} \%)$ & $3(13 \%)$ & I6 (12\%) \\
\hline Negative History & $13(72 \%)$ & II $(45 \%)$ & $53(4 \mathrm{I} \%)$ \\
\hline Totals & $\overline{18}$ & & \\
\hline
\end{tabular}

It will be noticed that the proportion of definite histories is much less among those who have lived abroad. It seems probable that in most, if not all, of the 13 negative histories of this group infection was acquired abroad, and this is a source of infection which should be guarded against.

\section{I.EPROSY OUTSIDE THE I.EPER ASYI.UM.}

Spot maps of Jamaica show that in rural areas leprosy is a focal disease. These have been particularly well traced out in the Trelawny parish by the Medical Officer of Health, and, as he points out, the disease began in the mountainous area to the south-west of the parish and is now tending to spread north-east to the lower areas (see spot-map of Trelawny). The group of foci in north-east Trelawny corresponds with similar groups in the adjoining areas of the neighbouring parishes of St. Ann, Manchester and Clarendon. The reason for grouping of these foci in this particular area between the two parishes is worthy of investigation. It has been suggested that it followed on the immigration of a certain group of settlers many years ago (see spot-map of Jamaica). 


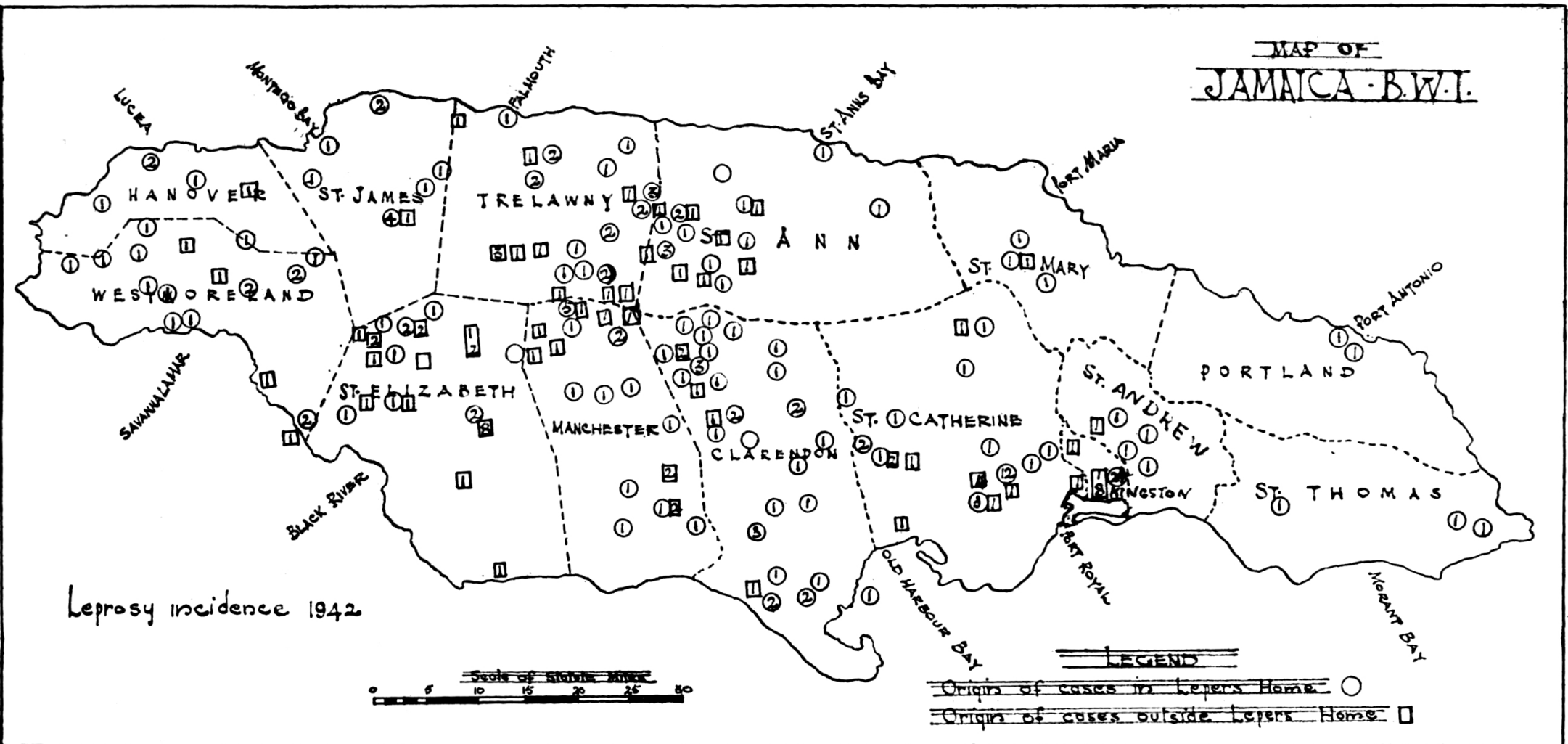


Table III shows the distribution of notified outside cases in the 14 parishes of Jamaica, along with the population of each parish:

Table III.

\begin{tabular}{|c|c|c|c|c|c|}
\hline Parish & & Female & Male & Total & Population \\
\hline Kingston $\quad \ldots$ & $\ldots$ & 3 & - & 3 & 85,906 \\
\hline St. Andrew & $\ldots$ & I & 4 & 5 & $65,28 \mathrm{I}$ \\
\hline St. Thomas & $\ldots$ & - & I & I & 53,331 \\
\hline Portland $\quad \ldots$ & $\ldots$ & - & I & I & 64,159 \\
\hline St. Mary ... & $\ldots$ & - & I & I & 94,530 \\
\hline St. Ann $\quad \ldots$ & $\ldots$ & 3 & 7 & IO & 103,570 \\
\hline Trelawny ... & $\ldots$ & 7 & 3 & IO & 48,796 \\
\hline St. James ... & $\ldots$ & I & - & I & 60,312 \\
\hline Hanover & $\ldots$ & I & I & 2 & 54,094 \\
\hline WYestmoreland & $\ldots$ & 3 & - & 3 & 95,685 \\
\hline St. Elizabeth & $\ldots$ & 6 & I 2 & 18 & I I 3,756 \\
\hline Manchester & $\ldots$ & 5 & 7 & I 2 & 92,899 \\
\hline Clarendon & $\ldots$ & 5 & 5 & IO & I 20,223 \\
\hline St. Catherine & $\ldots$ & 7 & 5 & I 2 & I 25,943 \\
\hline & & - & $\overline{7}$ & $\overline{80}$ & \\
\hline & & $\begin{array}{l}4^{2} \\
\end{array}$ & 47 & $\begin{array}{l}89 \\
-\end{array}$ & 170,485 \\
\hline
\end{tabular}

That this list is not $\mathrm{b}_{;}$any means complete is shown by a one-day visit I paid to the Trelawny parish. In company with the Medical Officer of Health I saw I4 cases, but had not time to see another three known to the Medical Officer of Health. Three of the 14. cases were seen for the first time, one being found in examination of the 64 pupils present in 7 school, another in the cottage of a previously known case, and the third previously suspected but not seen by the Medical Officer of Hoalth. Of the 14 cases seen, one showed no signs of having leprosy but was suffering from tinea flava resembling lepresy; another showerd no signs of leprosy; four were cases of arrested disease with deformity; two were early neural $(\mathrm{N}-\mathrm{I})$ cases; five were more advanced $(\mathrm{N}-2)$ cases; one was an advanced neural case with positive nasal findings ( $\mathrm{I}-\mathrm{I}, \mathrm{N}-3$ ). Of the three which were not scen, the description indicated that one was an open, lepromatous case, and the other two probably had arrested disease with deformity.

The visit to Trelawny parish shows: (a) the need for examination of schoolchildren, especially in known endemic areas: (h) that doctors, and especially Medical Officers of Health, should be familiar with the complex clinical signs of 


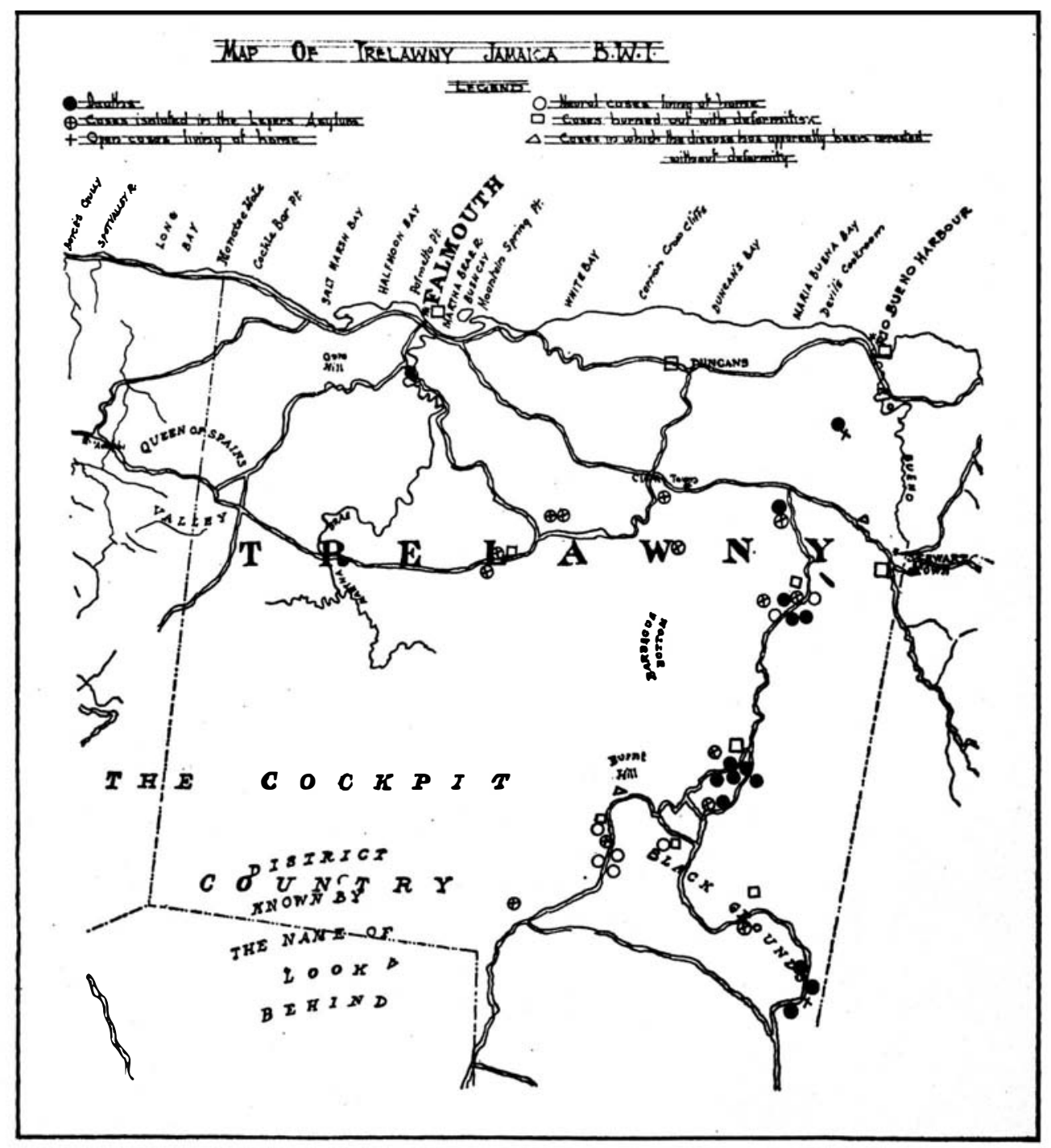

leprosy, so that they may not only diagnose leprosy, but be able to classify and recognise the signs of active disease; (c) the importance of distinguishing infectious cases, early neural cases which can often recover after a few months' suitable treatment, and arrested and advanced closed neural cases in which the disease is unlikely to recrudesce and which require only very occasional supervision. For early neural cases, such as the three new cases mentioned above, weekly out-patient treatment with chaulmoogra preparations would be suitable, but the distance to be travelled in most instances make this 
impracticable. It would be better to arrange for their admission to the Spamsh lown mstitution for a few months, but it would be necessary to allot special quarters for their reception so as to avoud as 1 ar as possible nixing with infectious patients and the danger of superinfection.

Examination for leprosy in schools should form part of general health examinations, and those undertaking such examinations should be familiar with the early signs of leprosy. Children should be entirely stripped, otherwise lesions may be overlooked.

Care should be specially concentrated on the effective isolation of all "open" cases. I made a separate examination of 19 patients who were admitted to the institution during the last 12 months. Of these, 12 were open cases, and I calculated that each of these must have been a potential spreader of infection for from two to five years before admission. Many "open" cases living in their own homes are in outlandish places where the Medical Officer of Health, with all his other duties, can only visit them at long intervals. Not infrequently" after a long journey on foot he finds them " not at home." lerusal of the records shows that some of these cases have been responsible for handing on the disease from generation to generation to relations and neighbours. I have dealt below with the laws regulatıng leprosy, but I consider that the regulations controlling "open" cases should be strengthened, and rigorously enforced when necessary.

Another difficulty in the path of control is the unpopularity of the Leper Asylum. I am told that none of the present paients have sought voluntary admission, with the exception of a few who have been forced in by extreme poverty. This is very different from the Trinidad leprosarium, where the majority seek voluntary admission and the law has seldom to be invoked.

\section{LEPROSY LAWS.}

The control of leprosy in Jamaica is governed by two separate laws: the unrevised I eper Asylum Law of 1896, and the Public Health Law amended up to 1942.

According to the former, leprous patients can be admitted in one of three ways :

(a) Under Section 6 the removal of leprous patients to the Asylum is in the hands of the Resident Magistrate, who upon its being certified to him by a registered Medical Practitioner that a person is a leper, and by two Justices 
of the Peace that he is too poor to look after himself, may make an order that he is to be admitted to the Leper Asylum.

(b) Under Section 7, the Resident Magistrate may take proceedings against anyone afflicted with leprosy, if he is proved to have been wandering about, begging, collectıng alnis, seeking precarious support or exposing himsclf in public places. Upon the oath of any registered Medical Practitioner that this person is afflicted with leprosy, it is lawful for the Magistrate to make an order, subject to the approval of the Ciovernor, for his removal to a Leper Asylum, unless security is given by a bond with one or more sureties to the amount of $£ 20$ that he shall be properly maintained and treated in private, and shall not be permitted to be at large.

(c) Voluntary patients who are able to contribute to their support can be admitted without reference to a Magistrate.

1he discharge of a patient trom the Leper Asylum is governed by his avility to provide or have provided a securit, o1 Ł20 similar to that auove.

under the rublic Heaith Law, leprosy is included among inlectious diseases which have to be notitned by all registered meuical practitioners to eitiner the Local, or the Lentral, Board of riealtn. Under this Law the person sultering irom thi intectious disease may (a) be isolated at his home it it is consiciered suitable, or can be rendered suitable by appropriate means, or (b), if this is not considered practicable, he may be removed, if necessary by force, to an isolation station or nospital.

Under the Leper Asylum Law, the criterion for removal to isolation is a "'means test," the ability of the patient to maintain himself according to a certain standard. Under the Public Health Law the criterion is one of infectiousness and the danger of the spread of disease to the public. There is a conflict between the two laws in that power to isolate under the Public Health Law does not give power to isolate in the Leper Asylum, since admission to the Leper Asylum is governed by a separate law.

Since 1896, when the L.eper Asylum Law was drafted, ideas about leprosy have changed. It is now realised that the deformed leper begging in the street, though revolting to look upon, is not an important source of infection. In him the 
disease may have died out, leaving only scars, and he mav be no more able to transmit leprosy than a pock-marked person can transmit smallpox. The chief danger is from the "open" case which, as the disease advances, is recognised by nodules and thickenings, especially of the face and ears, but which, to begin with, may show no easily recognised signs. Moreover, the place of danger is not the street but the home. Leprosy is spread by close contact to the child in arms, and then in a diminishing degree to those who share the bed, the room, the house, and those who come into occupational or social contact.

The Leper Asylum Law deals with leprosy either as an intrrmity or an ollence, to be controlled by the Poor Relief Agent or the police. 1 he Public Health Law regards leprosy as an infectious disease, but, as far as isolating patients in the Leper Asylum and discnarging them again, the special law Iunctions.

In British Guiana, Trinidad and other British West Indies the 1eprosy Act arranges for the removal of all cases to the leprosy institution. Uniy cases in which the disease is slight and of the "closed" (neural) type are permitted to remain outside. Moreover, the control of leprosy in these colonies is in the hands of the Public Health Authorities. Recently, an up-to-date, revised dratt of the Trinidad Leprosy Act has been prepared; I suggest that the Jamaica Leprosy Law be based upon similar lines. Meanwhile, perhaps, rules might be made to facilitate the admission and make more difficult the discharge or abscondence of " open" cases.

I would suggest tnat a complete confidential list be made of persons. in Jamaica sulfering or formerly suffering from leprosy, classitying them under the following groups:

(a) “Open," L-I, L-2, L-3; “closed," N-I, N-2. N-3; arrested.

(b) Segregated in the Leper Home; living outside the Leper Home.

(c) Division according to parishes and districts.

(d) Contacts of infectious cases, and a record of their repeated examinations.

(e) A list of new cases found each year, especially among contacts and on school examination.

It might be the duty of one officer specially trained in this work, in consultation with the Medical Officer of Health, to keep these lists up to date. 
STAFF, TRAINING AND EDUCATION.

The sine qua non of leprosy control is the provision of one doctor who would be given an opportunity of at least threc months' training in a well-organised leprosy institution such as that in Irinidad. This man on his return to Jamaica would undertake an island survey and be placed in charge of the Leper Asylum.

In addition to this, arrangement should be made for health officers to undergo a short period of training, say three months, at the I.eper Asylum with this officer. Such an arrangement at present exists in Trinidad, where it has already been tound to be most valuable in the control of the disease

The Sisters in charge of the Leper Home have suggested that one of their number should spend a similar period at Chacachacare, where she could study dentistry, laboratory methods and the routine work of the leprosarium. I shall be glad to give facilities if this can be arranged.

As elsewhere, one of the chief difficulties in the control of leprosy is the misconceptions which are present regarding leprosy. The general public consider the disease hereditary and are fatalistic about the spread of infection. Doctors and educated nembers of the public tend, on the other hand, to have an undue fear of the disease quite out of proportion to any danger involved when simple precautions are observed. Education of the public through an enlightened medical profession, and especially through the Medical Officers of Health, should gradually remove these misconceptions.

\section{CONCLUSIONS.}

Strictly, from the standpoint of morbidity and mortality, leprosy is not a major disease in Jamaica. Leprosy remains endemic below a certain level of sanitation and standard of living. In some parts of Jamaica this level has been surmounted, in others it has not. But those at the higher level must suffer the danger as long as those at the lower level remain.

There are two main reasons why leprosy should be treated as more important than its mortality and morbidity would seem to warrant. It is held in far more horror than other more fatal diseases, indeed its non-fatality and the long, living death to which it sentences its victims make it more dreaded than any other disease. The other reason is the comparative ease with which leprosy could be controlled if a definite persistent policy were adopted along the right lines. 
In the above pages I have madr suggestions in accordance with my experience of leprosy in other countries and my short study of conditions in Jamaica. They may be summarizerd as follows :

I. There is urgent need for improvements in the Leper Asylum. In the past it has been an Asylum, a place of refuge for those suffering from a hopeless infirmity. What is required is a leprosy sanatorium or leprosarium where cases can be admitted as soon as possible with even more hope of recovery than in a well-conducted tuberculosis sanatorium. The site is wrong, the buildings are unsuitable and congested, but much can be done to iniprove these short of the (at present) difficult task of erecting a new institution on a fresh site. For the last two years definite improvements have been made under the care of the sisters, and they should be given every possihle facility and help. A whole-time doctor for leprosy work who has had a chance of studying leprosy elsewhere is essential. Occupation and living interests are needed as the most important part of treatment and render more cheerful the life of the patients.

The improvement of the institution along such lines should render it more attractive and gradually lead to more voluntary admissions and better discipline.

2. A clearer distinction should be made between "open " and "closed" cases. The former should be allowed to live outside the institution only when certain strict rules are complied with and adequate medical supervision is possible to prevent the spread of infection. The law. should be amended so as to give adequate power to the Public Health Authorities. Considerable room could be created in the Leper Home by discharging patients in whom the disease has died out and, later, others who would reach this condition in a short time by means of treatment. These could be quartered near their relatives, assistance being given for their maintenance.

3 A survey is required with special regard to the contacts of "open" cases and schoolchildren. Record of all cases and contacts should be made in consultation with the Medical Officers of Health and the lists kept up to date. All doctors should be given an opportunity to familiarise themselves with the diagnosis and classification of leprosv and the means of control. The public should be educated in the nature and dangers of leprosy. 


\section{ACKNOWLEDGMENTS.}

I wish to thank the Director and Assistant Director of Medical Services, the Government Bacteriologist and other Medical Officers for the arrangements that they made for my studies in Jamaica, and the Medical Officer of the Leper Asylum and Sisters for all the help they have given at that institution. I wish also to acknowledge with thanks the financial arrangements made by the Comptroller and his Medical Adviser. I found the assistance of Mr. I. E. Davies of considerable value 